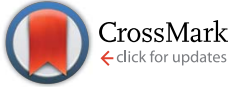

Cite this: RSC Adv., 2017, 7, 10748
Received 16th December 2016 Accepted 1st February 2017

DOI: $10.1039 / c 6 r a 28290 c$

rsc.li/rsc-advances

\section{Synthesis of environmentally friendly, efficient and highly recyclable Lewis acid-type calix[4]arene catalysts containing flexible or bulky groups for the Mannich reaction $\dagger$}

\begin{abstract}
Serkan Sayin ${ }^{\star a}$ and Mustafa Yilmaz ${ }^{\mathrm{b}}$
Two new calix[4]arene-based Lewis acid-type catalysts containing flexible and bulky groups (2 and 3) were successfully synthesized. Their structures were characterized using FTIR, ${ }^{1} \mathrm{H}-\mathrm{NMR}, \mathrm{COSY}-\mathrm{NMR},{ }^{13} \mathrm{C}-\mathrm{NMR}$, APT-NMR, and elemental analysis techniques. Moreover, to provide easily recyclable, environmentally benign, cost effective and reusable catalysts, these calix[4]arene-based Lewis acid-type catalysts were grafted onto epoxyl-functionalized silica-coated $\mathrm{Fe}_{3} \mathrm{O}_{4}$ magnetic nanoparticles (EPPTMS-MN) to afford their corresponding calixarene-grafted magnetic nanoparticles (TMAC[4]Bu ${ }^{t}-\mathrm{MNP}$ and $\mathrm{P}(\mathrm{Ph}){ }_{3} \mathrm{C}[4] \mathrm{Bu}^{t}-$ MNP). FTIR, TGA, TEM, VSM and elemental analysis techniques were performed to confirm their structures. In addition, the catalytic capabilities of four Lewis acid-type calixarene catalysts were evaluated in a three component Mannich reaction of benzaldehyde with aniline and acetophenone in aqueous media without co-solvents. The association of the effects of functional groups (flexible and bulky), molar equivalents, amount of water used, and reaction durations on their catalytic efficacies were also evaluated.
\end{abstract}

\section{Introduction}

The Mannich-type reaction and other related reactions requiring a catalyst are known as simple and substantial approaches for producing $\beta$-amino carbonyl compounds, which are potential intermediates for the fabrication of pharmaceutical agents and synthetically utilizable $\mathrm{N}$-containing substances, via the reactions involving carbon-carbon bond formation. ${ }^{1-5}$ Numerous catalysts such as Brönsted-type acids, Lewis-type acids and several organic or inorganic catalysts have been developed to catalyze Mannichtype reactions. ${ }^{3,6-11}$ However, generally organic solvents or organic solvent-water mixtures are chosen as a medium for Mannichtype reactions due to the drastic solubility of most of the developed catalysts. ${ }^{9-13}$ In view of the toxicological effects of any organic solvent containing mixtures to the environment as well as human beings, developing a method for $\mathrm{C}-\mathrm{C}$ bond construction via Mannich reactions in water is a challenging but important task in the field of green chemistry. ${ }^{\mathbf{1 4}}$ Therefore, researchers continue to focus more attention on developing efficient catalysts that can be run in an aqueous media for Mannich-type reactions producing $\beta$-amino carbonyl compounds.

${ }^{a}$ Department of Environmental Engineering, Faculty of Engineering, Giresun University, Giresun-28200, Turkey. E-mail: serkan.sayin@giresun.edu.tr; Fax: +90 454 3101749; Tel: +904543101740

${ }^{b}$ Department of Chemistry, Selcuk University, Konya-42075, Turkey

$\dagger$ Electronic supplementary information (ESI) available. See DOI: 10.1039/c6ra28290c
Calixarenes, produced via a condensation reaction of $p$ substituted phenols and formaldehyde, represent very useful building blocks. ${ }^{15-17}$ Because of their simple structural modification and unique structural properties, such as having differentsized cavities and comprising both hydrophilic and hydrophobic sites, a large number of applications of calixarenes in supramolecular chemistry have been reported. ${ }^{\mathbf{1 8 - 2 1}}$ More recently, chemists are devoting greater attention to developing efficient calixarene-based catalysts to facilitate $\mathrm{C}-\mathrm{C}$ bond formation in water. ${ }^{4,22,23}$

In our previous study, we designed a calix[4]arene-based quaternary ammonium salt containing 1-(2-furoyl)piperazine groups as a catalyst for three component Mannich reactions of benzaldehyde with aniline and acetophenone in water. ${ }^{4}$ We found that this calix[4]arene salt efficiently catalyzed the Mannich reaction to synthesize corresponding $\beta$-aminocarbonyl compounds in high yield during a short period of time. ${ }^{4}$ In this study, we have preliminarily adopted a strategy that involves the introducing flexible and bulky groups to Lewis acid-type calix[4] arene derivatives in order to elucidate their effects on the catalytic properties of calixarene-based catalysts. Thus, we successfully achieved the syntheses of two new calix[4]arene derivatives involves the introduction of flexible and bulky groups at the lower rim of calixarene. In addition, for the first time, these Lewis acid-type calix[4]arene derivatives were grafted onto an epoxysilica-coated $\mathrm{Fe}_{3} \mathrm{O}_{4}$ magnetic nanoparticle surface. From the standpoint of green 
chemistry, this method provides them with easily recyclable, environmentally benign, cost effective and reusable catalysts. Furthermore, their catalytic activities were investigated for the first time in the three component Mannich reaction of benzaldehyde with aniline and acetophenone in water without cosolvents.

\section{Results and discussion}

Synthesis of new Lewis acid-type calix[4] arene derivatives (2, 3 ), and their corresponding magnetic nanoparticles (TMAC[4] $\left.\mathrm{Bu}^{t}-\mathrm{MNP}, \mathrm{P}(\mathrm{Ph})_{3} \mathrm{C}[4] \mathrm{Bu}^{t}-\mathrm{MNP}\right)$

In our previous study, the catalytic capability of a calix[4]arenebased quaternary ammonium salt containing 1-(2-furoyl)piperazine groups were investigated in three component Mannich reactions of benzaldehyde with aniline and acetophenone in water. $^{4}$ We found that 1-(2-furoyl)piperazine-functionalized calix[4]arene-based quaternary ammonium salt exhibited efficient catalytic behavior for the synthesis of a $\beta$-aminocarbonyl compound. ${ }^{4}$ Inspired by our results, ${ }^{4}$ in this study we aimed to extend the variety of Lewis acid-type calixarenes and to exploit the effects of flexible (containing alkyl quaternary-ammonium) and bulky (containing triphenylphosphonium) groups of Lewis acid-type calix[4]arene derivatives $(2,3)$ on their catalytic abilities in three component Mannich reactions of benzaldehyde with aniline and acetophenone in an aqueous media. Furthermore, these Lewis acid-type calix[4]arene derivatives $(2,3)$ were grafted for the first time onto silica-modified $\mathrm{Fe}_{3} \mathrm{O}_{4}$ magnetic nanoparticles in order to apply them as a Lewis acid-type catalyst in three component Mannich reactions in water without cosolvents. For this purpose, p-tert-butylcalix[4]arene (1) was synthesized according to literature procedure. ${ }^{24}$ The substitution of $p$-tert-butylcalix[4]arene (1) at the lower rim was conducted with (5-bromopentyl)trimethylammonium bromide and (3-bromopropyl)triphenylphosphonium bromide to form 25,27-bis[5-(trimethylammonium bromide)pentyloxyl]-26,28dihydroxyl-5,11,17,23-tetra-tert-butylcalix[4]arene (2) and 25,27bis[3-(triphenylphosphonium bromide)propyloxyl]-26,28-dihydroxyl-5,11,17,23-tetra-tert-butylcalix[4]arene (3) with a yield of $85 \%$ and $91 \%$, respectively (Scheme 1). FTIR, ${ }^{1} \mathrm{H}-\mathrm{NMR},{ }^{13} \mathrm{C}-$ NMR, COSY-NMR, ${ }^{13} \mathrm{C}-\mathrm{APT}$ NMR, and ${ }^{31} \mathrm{P}-\mathrm{NMR}$ spectroscopy and elemental analysis techniques were performed for the structural elucidation of Lewis acid-type calix[4] aren derivatives. The FTIR spectra of Lewis acid-type calix[4]arene derivatives (2 and 3) (Fig. S1 and S2; see $\mathrm{ESI} \dagger$ ) gives compatible information about their structures to the NMR spectra.

${ }^{1} \mathrm{H}-\mathrm{NMR}$ spectrum and two dimensional COSY-NMR spectrum, which leads to assign the interactions between the peaks (Fig. S3 and S4; see ESI $\dagger$ ), of Lewis acid-type calixarene 2, indicated that the quaternary-ammonium with long alkyl subunits were successfully attached to at the lower rim of $p$-tert-butylcalix [4] arene, which resonances at 1.75-2.07 $(12 \mathrm{H}), 3.45(18 \mathrm{H}), 3.76$ $(4 \mathrm{H})$, and $3.96(4 \mathrm{H}) \mathrm{ppm}$ for the protons of the $-\mathrm{CH}_{2},-\mathrm{CH}_{3}$, $-\mathrm{OCH}_{2}$, and $-\mathrm{NCH}_{2}$ groups, respectively (Fig. S3; see ESI $\dagger$ ). Moreover, a ${ }^{13} \mathrm{C}-\mathrm{NMR}$ spectra of the derivative 2 also contributed to our determination of its structure through the appearance of characteristic peaks at 22.8, 22.9 and $29.2 \mathrm{ppm}$ for
$-\mathrm{CH}_{2}-$, as well as at $33.9,53.5$, and $66.6 \mathrm{ppm}$ for the $-\mathrm{N}^{+}-\mathrm{CH}_{3}$, $-\mathrm{N}^{+}-\mathrm{CH}_{2}-$, and $-\mathrm{O}-\mathrm{CH}_{2}-$ groups (Fig. S5; see ESI $\dagger$ ).

The appeared peaks at $2.03(4 \mathrm{H}), 3.93(4 \mathrm{H}), 4.07(4 \mathrm{H})$ and 7.60-7.77 $(30 \mathrm{H}) \mathrm{ppm}$ for the protons of the $-\mathrm{CH}_{2},-\mathrm{OCH}_{2}$, $-{ }^{+} \mathrm{PCH}_{2}$, and aromatic units of triphenylphosphonium groups, respectively in the ${ }^{1} \mathrm{H}$-NMR spectra of Lewis acid-type calix[4] arene bearing bulky groups 3 clearly indicate that the substitution of $p$-tert-butylcalix[4]arene with triphenylphosphonium moieties was successfully achieved (Fig. S6; see ESI†).

The ${ }^{13}$ C-NMR (Fig. S7; see ESI $\dagger$ ) and APT- ${ }^{13}$ C-NMR spectra of Lewis acid-type calix[4]arene 3 also contributed to determine its structure. The peaks belonging to the $-\mathrm{CH}_{3}$ (two peaks at 30.8 and $31.1 \mathrm{ppm}$ for tert-butyl groups) and - $\mathrm{CH}$ (five peaks at 125.2, 125.5, 130.6, 133.6 and $135.3 \mathrm{ppm}$ for aromatic units) groups appeared at the positive region, while the peaks for the $-\mathrm{CH}_{2}$ (four peaks at 19.6, 22.7, 31.6 and $74.5 \mathrm{ppm}$ ) and quaternary $-\mathrm{C}$ (eight peaks at 33.7, 33.8, 117.3, 118.1, 127.8, 131.7, 142.2, 147.1 and $148.7 \mathrm{ppm}$ ) groups assigned at the negative region (Fig. S8; see ESI $\dagger$ ). The peaks in the ${ }^{31} \mathrm{P}-\mathrm{NMR}$ spectra of derivative 3 also confirmed that Lewis acid-type calix[4]arene 3 contained phosphonium groups (Fig. S9; see ESI $\dagger$ ).

Preparation of $\mathrm{Fe}_{3} \mathrm{O}_{4}$ nanoparticles and [3-(2,3-epoxypropoxy)propyl]-trimethoxysilane-coated $\mathrm{Fe}_{3} \mathrm{O}_{4}$ nanoparticles (EPPTMS-MN) was carried out according to literature procedures ${ }^{25}$ in order to fabricate Lewis acid-type calix[4] arenes-grafted $\mathrm{Fe}_{3} \mathrm{O}_{4}$ magnetic nanoparticles that were employed as a catalyst in three component Mannich reactions in water without co-solvents. For this goal, 25,27-bis[5-(trimethylammonium bromide)pentyloxyl]-26,28-dihydroxyl-5,11,17,23-tetra-tert-butylcalix[4]arene (2) and 25,27-bis[3-(triphenylphosphonium bromide)propyloxyl]-26,28-dihydroxyl-5,11,17,23-tetra-tert-butylcalix[4]arene

(3) were grafted onto EPPTMS-MN to afford their corresponding nanoparticles, TMAC[4] $\mathbf{B u}^{t}-\mathbf{M N P}$ and $\mathbf{P}(\mathbf{P h})_{\mathbf{3}} \mathbf{C}[\mathbf{4}] \mathbf{B u}^{\boldsymbol{t}}$-MNP (see Scheme 1). Their structures were estimated using a combination of FTIR spectroscopy, TEM, TGA and elemental analysis.

The FTIR spectra presented in ESI $\dagger$ and the appearance of notably characteristic IR peaks at 1482,1439 and $1412 \mathrm{~cm}^{-1}$ for TMAC[4] Bu ${ }^{t}$-MNP and 1479, 1458 and $1408 \mathrm{~cm}^{-1}$ for $\mathbf{P}(\mathbf{P h})_{3} \mathbf{C}[\mathbf{4}]$ $\mathbf{B u}^{t}-\mathbf{M N P}$ all of which are stretching vibrations of aromatic $\mathrm{C}=\mathrm{C}$ bands of Lewis acid-type calix[4]arenes 2 and 3 clearly implied the accuracy of their structures (Fig. S1 and S2; see ESI $\dagger$ ). Additional peaks indicating the stretching vibrations of the SiO groups of the silica part of EPPTMS-MN appeared at 1072, 955 and $794 \mathrm{~cm}^{-1}$ for TMAC[4] Bu ${ }^{t}$-MNP and 1152, 1081, 953 and $793 \mathrm{~cm}^{-1}$ for $\mathbf{P}(\mathbf{P h})_{3} \mathbf{C}[\mathbf{4}] \mathbf{B u}^{t}-\mathbf{M N P}$.

To determine the particle size and morphological distribution of the $\mathrm{Fe}_{3} \mathrm{O}_{4}$, TMAC[4] $\mathbf{B u}^{t}-\mathbf{M N P}$ and $\mathbf{P}(\mathbf{P h})_{3} \mathbf{C}[4] \mathbf{B u}^{t}-\mathbf{M N P}$, a Transmission Electron Microscopy (TEM) was used (see Fig. 1). Fig. 1a indicates that the $\mathrm{Fe}_{3} \mathrm{O}_{4}$ nanoparticle had a particle size of $8 \pm 3 \mathrm{~nm}$. It also indicates that due to the magnetite properties of the particles, the particles created a magnetic field, resulting with piled up particles. However, the immobilization of calixarene derivatives, which have no magnetic features, worked to decrease this magnetic field and caused the distribution of the particles. Indeed, the electrostatic repulsion force and steric hindrance between the calixarenes also contributed to the particles' distribution. In addition, we 


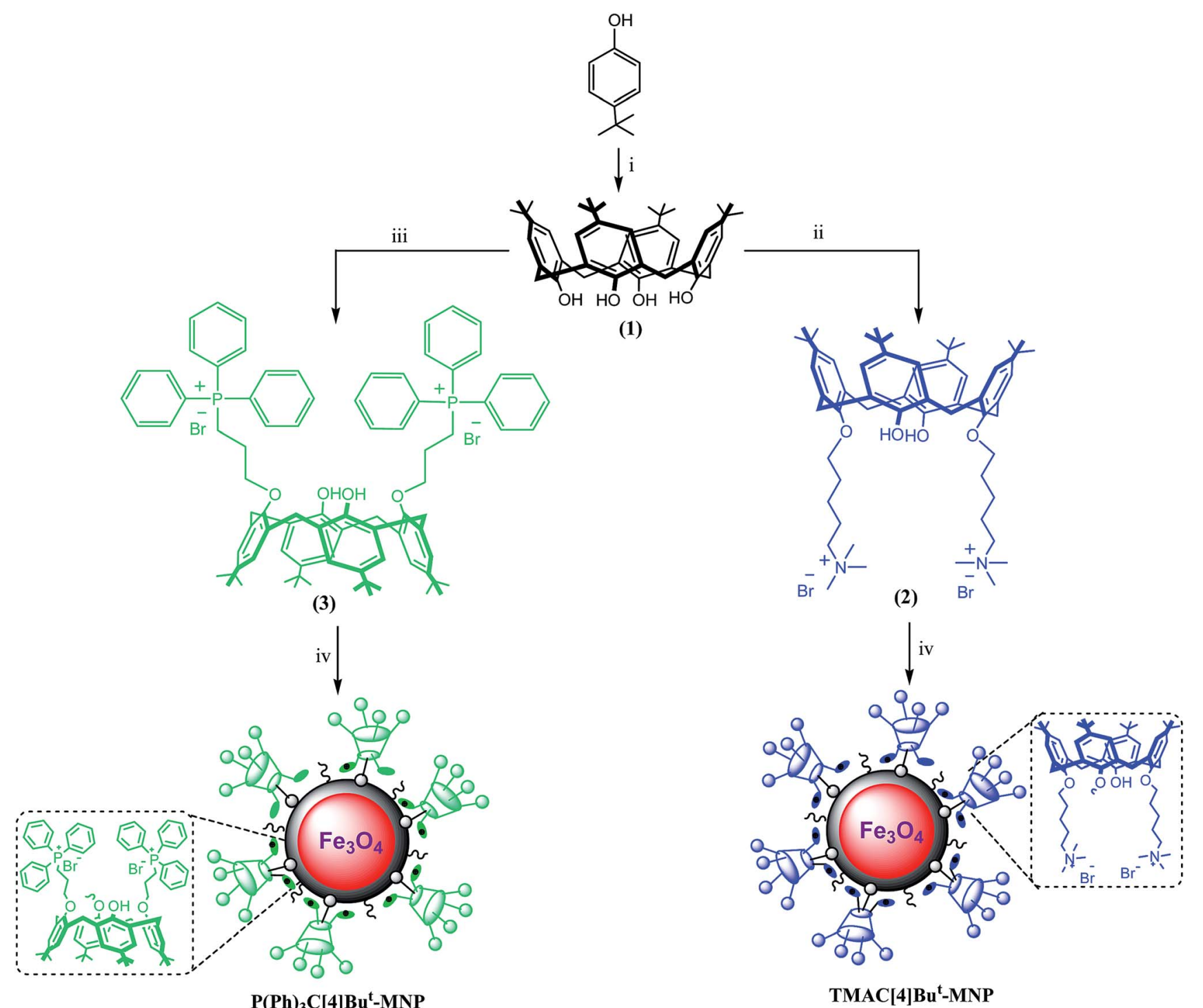

Scheme 1 Synthesis of Lewis acid-type calix[4]arene derivatives. Reaction conditions; (i) $\mathrm{HCHO}, \mathrm{NaOH}$; (ii) (5-bromopentyl)trimethylammonium bromide, $\mathrm{K}_{2} \mathrm{CO}_{3}$; (iii) (3-bromopropyl)triphenylphosphonium bromide, $\mathrm{K}_{2} \mathrm{CO}_{3}$; (iv) EPPTMS-MN, $\mathrm{NaH}$.

found the size of particles that were 8-10 $\mathrm{nm}$ larger than the typical particle size of the $\mathrm{Fe}_{3} \mathrm{O}_{4}$ nanoparticle. The reason was probably the intermolecular interaction between calixarene parts of the nanoparticles caused the particles to aggregate.

To explore the amount of grafted calixarene derivatives onto the silica-coated magnetic nanoparticles, the elemental analysis technique was carried out. The results for TMAC[4] $\mathbf{B u}^{t}-\mathbf{M N P}$, depicted in Table 1, show that 25,27-bis[5-(trimethylammonium bromide)pentyloxyl]-26,28-dihydroxyl-5,11,17,23-tetra-tert-butylcalix[4]arene ( 2 or Calix-2) was successfully grafted onto EPPTMS-MN. It was also found that TMAC[4] Bu${ }^{t}-\mathbf{M N P}$ contained $0.19 \%$ nitrogen, corresponding to $0.28 \mathrm{mmol}$ of derivative 2 per $\mathrm{g}$ of support.

We performed thermogravimetric analyses (TGA) of TMAC[4] $\mathbf{B u}^{t}-\mathbf{M N P}$ and $\mathbf{P}(\mathbf{P h})_{3} \mathbf{C}[4] \mathbf{B u}^{t}-\mathbf{M N P}$ to confirm the presence of Lewis acid-type calixarene derivatives on the surface of the $\mathrm{Fe}_{3} \mathrm{O}_{4}$ nanoparticles, as well as to investigate their thermal stabilities (Fig. 2). In the graph, the observed weight loss at 50$225{ }^{\circ} \mathrm{C}$ may be the result of the evaporated water and the other solvents (see Fig. 2). For TMAC[4] $\mathbf{B u}^{t}-\mathbf{M N P}$, the weight loss of $17.2 \%$ at $250-650{ }^{\circ} \mathrm{C}$ can be attributed to the degradation of calixarene units (2 or Calix-2) and 3-(2,3-epoxypropoxy)-propyl groups (see Fig. 2a) while the weight loss of EPPTMS-MN was about $5 \%$ within a broad temperature range of 250 to $650{ }^{\circ} \mathrm{C}$. For $\mathbf{P}(\mathbf{P h})_{3} \mathbf{C}[4] \mathbf{B u}^{t}-\mathbf{M N P}$, thermal degradation of calixarene units (3 or Calix-3) and 3-(2,3-epoxypropoxy)-propyl groups resulted with the weight loss of $25.5 \%$ at $275-900{ }^{\circ} \mathrm{C}$ (see Fig. 2b).

The magnetic properties of EPPTMS-MN, TMAC[4] Bu ${ }^{t}-\mathbf{M N P}$, and $\mathbf{P}(\mathbf{P h})_{3} \mathbf{C}[\mathbf{4}] \mathbf{B u}^{t}-\mathbf{M N P}$ were investigated using VSM (Lake Shore 7407) analysis at room temperature (see Fig. 3). Fig. 3 indicates that all the sample had a superparamagnetic behavior and saturation magnetization of EPPTMS-MN, TMAC[4] $\mathbf{B u}^{t}$ $\mathbf{M N P}$, and $\mathbf{P}(\mathbf{P h})_{3} \mathbf{C}[4] \mathbf{B u}^{t}-\mathbf{M N P}$ were found to be 44,32 and 23 


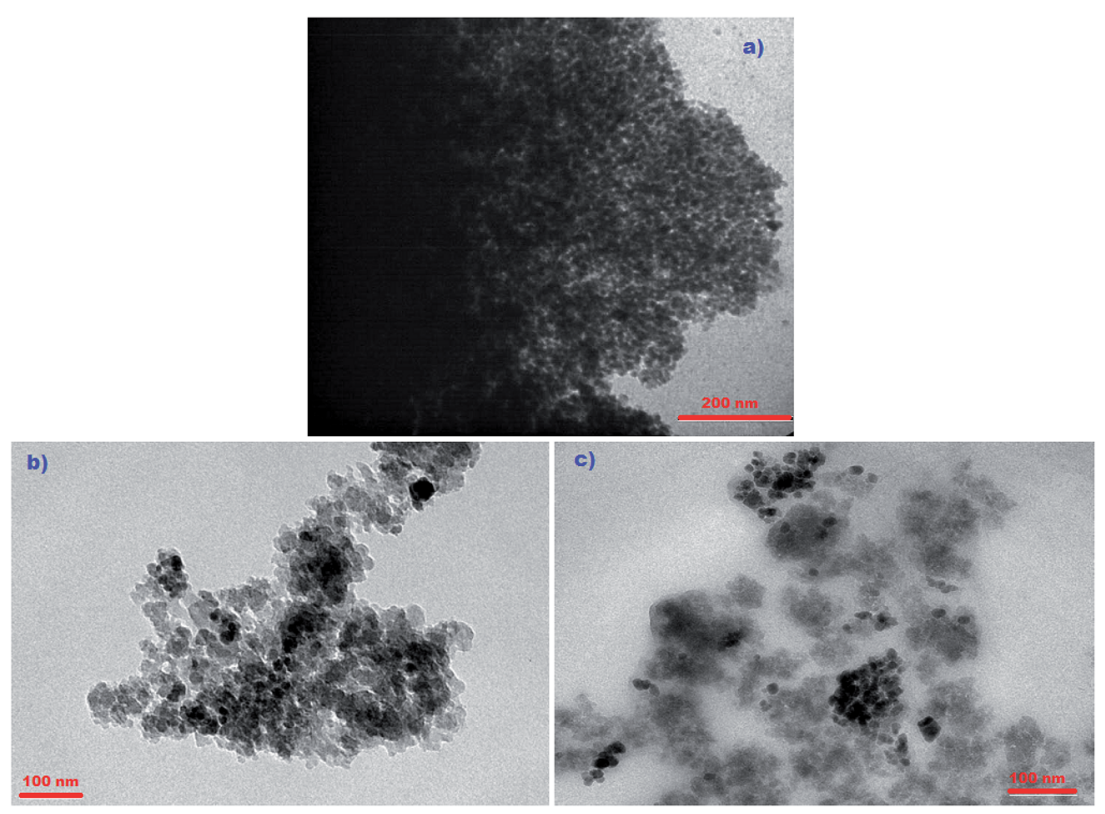

Fig. 1 TEM images of (a); $\mathrm{Fe}_{3} \mathrm{O}_{4}$ magnetic nanoparticles, (b); TMAC[4]But-MNP, (c); $\mathrm{P}(\mathrm{Ph}){ }_{3} \mathrm{C}[4] \mathrm{Bu}^{t}-\mathrm{MNP}$.

Table 1 Elemental analysis results of EPPTMS-MN and TMAC[4]ButMNP

\begin{tabular}{|c|c|c|c|c|}
\hline & $\mathrm{C}(\%)$ & $\mathrm{H}(\%)$ & $\mathrm{N}(\%)$ & $\begin{array}{l}\text { Bounded amount } \\
\left(\mathrm{mmol} \mathrm{g}^{-1}\right)\end{array}$ \\
\hline EPPTMS-MN $^{b}$ & 13.20 & 2.61 & & \\
\hline TMAC $[4] \mathrm{Bu}^{t}-\mathrm{MNP}$ & 16.24 & 3.51 & 0.19 & 0.28 \\
\hline
\end{tabular}

emu $^{-1}$, respectively. It can be clearly seen that immobilization of calixarene derivatives reduced the saturation magnetization value. However, it was an expected result because organic units onto the surface of magnetic nanoparticles were increased.

Evaluation of catalytic efficiencies of Lewis acid-type calix[4] arene derivatives (Calix-2 and Calix-3), and their corresponding magnetic nanoparticles (TMAC $[4] \mathrm{Bu}^{t}-\mathrm{MNP}$ and $\left.\mathbf{P}(\mathrm{Ph})_{3} \mathrm{C}[4] \mathrm{Bu}^{t}-\mathrm{MNP}\right)$

In our previous study, a calix[4]arene-based quaternary ammonium salt containing 1-(2-furoyl)piperazine groups was used as a Lewis acid-type catalyst in the three component Mannich reaction of benzaldehyde with aniline and acetophenone in water without co-solvents. ${ }^{4}$ It was observed that calix[4]arenequaternary ammonium salt exhibited significant catalytic efficacy for the Mannich reactions. This study aimed to elucidate the effects of flexible and bulky groups on the catalytic efficacy of Lewis acid-type calix[4] arene catalysts (Calix-2 and Calix-3) for the three component Mannich reaction in an aqueous media. Thus, for the first time, we conducted an experiment to study the catalytic capabilities of Lewis acid-type calix[4]arene derivatives containing flexible or bulky groups. In addition, their corresponding magnetic nanoparticles were also employed as
Lewis acid-type catalysts in a Mannich type reaction of benzaldehyde with aniline and acetophenone. From the experimental results depicted in Table 2 , it can be seen that the corresponding Mannich product 4 were not produced even after 7 days when the commercial tetrabutylammonium bromide (TBAB) was chosen as the catalyst. However, by increasing the reaction time to 19 days, the target compound 4 was produced in a trace yield in the presence of TBAB (Table 2, entry 2). When Lewis acid-type calix[4] arene derivatives (Calix-2 or Calix-3) were used as catalysts, good yields of the corresponding Mannich product 4 were afforded in a shorter reaction time (see Table 2). On our first attempt, the addition of $0.5 \mathrm{~mol} \%$ of Calix-2 and Calix-3 containing flexible and bulky groups (Table 2, entries 3 and 9) as catalysts in water $(16 \mathrm{~mL})$ to the three component Mannich reaction produced the $\beta$-aminocarbonyl compound 4 with the isolated yields of $52 \%$ for both of them after $6 \mathrm{~h}$ (Fig. S10 and S11; see the ${ }^{1} \mathrm{H}$ and ${ }^{13} \mathrm{C}$ NMR spectra of the Mannich adduct in the ESI $\dagger$ ). The molar equivalent of Calix-2 and Calix-3 was used as $1 \mathrm{~mol} \%$ under the same reaction conditions, and an increase on the value of the isolated yields of compound 4 was observed (Table 2, entries 4 and 10). However, using a 2 mol\% molar equivalent of Calix-2 and Calix-3 in $16 \mathrm{~mL}$ of $\mathrm{H}_{2} \mathrm{O}$ (Table 2, entries 5 and 11) gave lower yields of the corresponding product 4, 35 and $27 \%$, respectively after 6 h. This decrease on the isolated yields led us to consider that changing the other parameters such as the amount of water used or the reaction duration might increase the isolated yield of $\mathbf{4}$. Indeed, we found that increasing the reaction time resulted with higher yields (Table 2, entries 8 and 15). Moreover, using $3.5 \mathrm{~mL}$ of $\mathrm{H}_{2} \mathrm{O}$ in the presence of Calix-2 provided the highest recorded yield, $69 \%$ (Table 2, entry 6), whereas the lowest yield of the corresponding product 4 was obtained using $1.8 \mathrm{~mL}$ of $\mathrm{H}_{2} \mathrm{O}$ in the presence of Calix-2 (Table 2, entry 7). Changing the amount of water used with Calix-3 as the catalyst yielded similar results. 


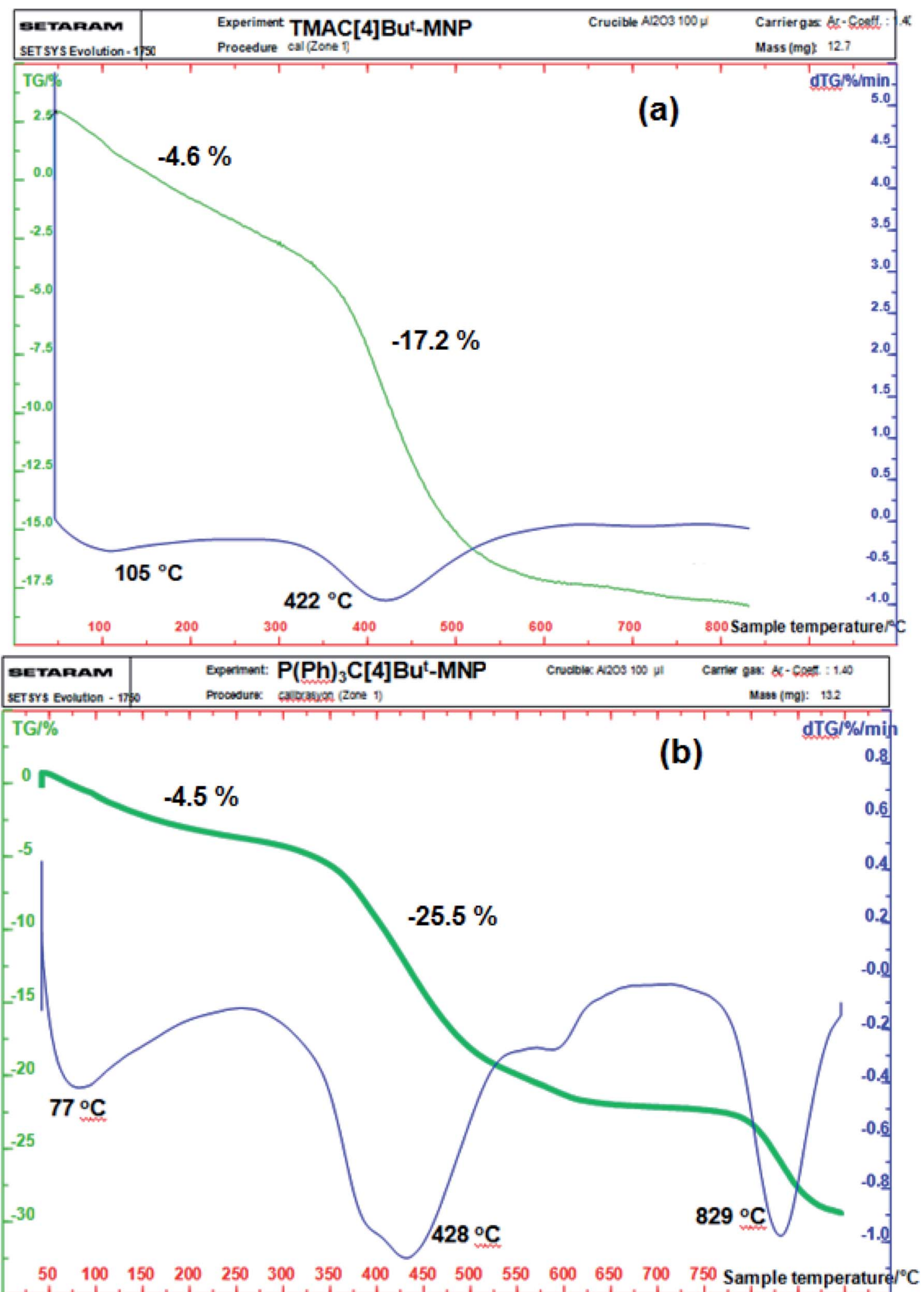

Fig. 2 TGA curves of (a) TMAC[4]Bu ${ }^{t}-M N P$, and (b) $P(P h)_{3} C[4] \mathrm{Bu}^{t}-M N P$.

However, the highest yield of Mannich product $\mathbf{4}$, as high as $77 \%$, using catalyst Calix-3 (2 mol\%) was obtained when we applied a $24 \mathrm{~h}$ reaction parameters using $1.8 \mathrm{~mL}$ of $\mathrm{H}_{2} \mathrm{O}$ (Table
2 , entry 15$)$. This finding suggests that the bulky groups contained in Calix-3 exhibited better catalytic efficacy than the flexible units contained Calix-2. 


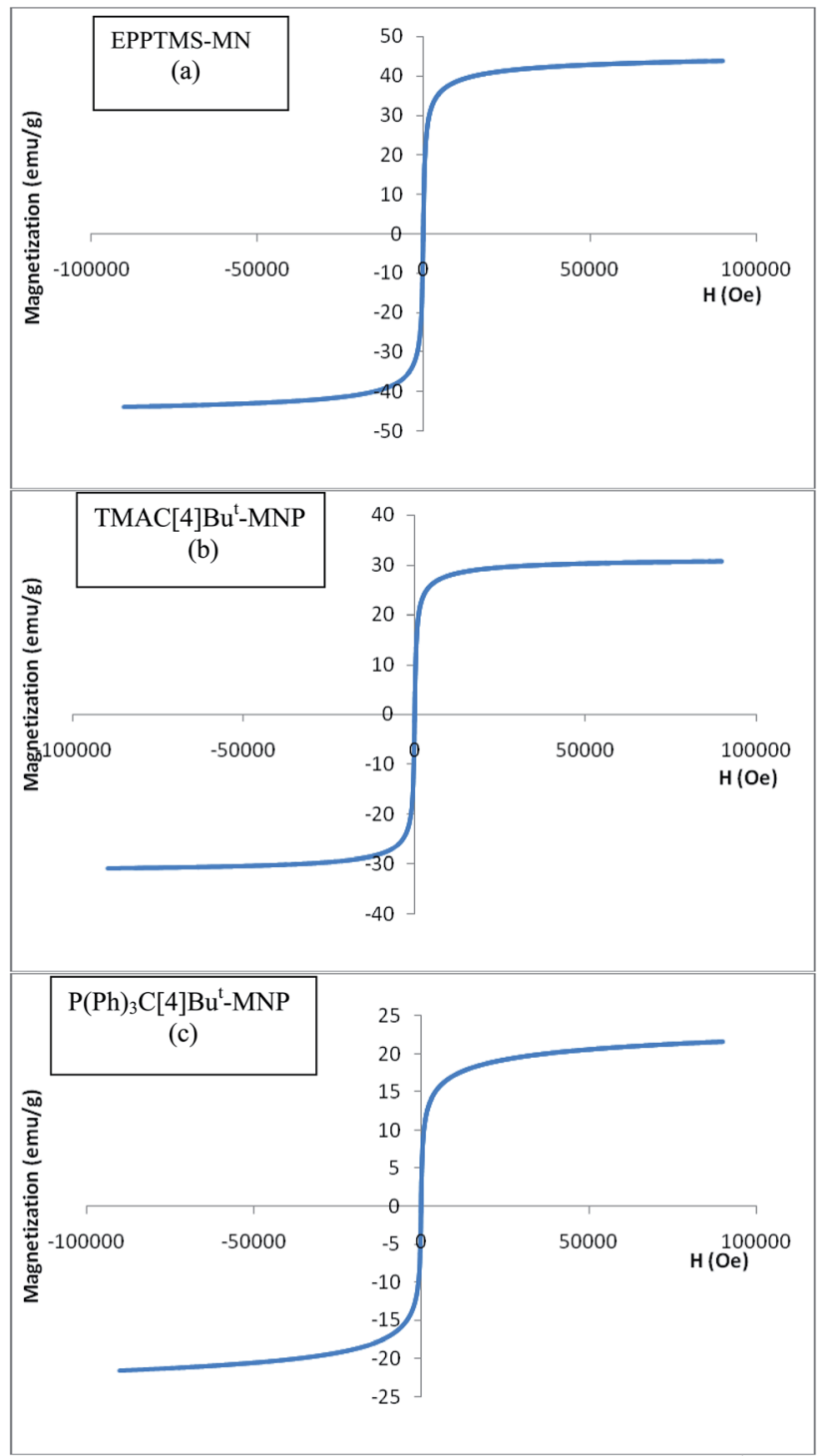

Fig. 3 Magnetization curves of (a) EPPTMS-MN, (b) TMAC[4]Bu ${ }^{t}-M N P$, and (c) $\mathrm{P}(\mathrm{Ph})_{3} \mathrm{C}[4] \mathrm{Bu}^{t}-\mathrm{MNP}$

The catalytic properties of EPPTMS-MN, TMAC[4] $\mathbf{B u}^{t}-\mathbf{M N P}$ and $\mathbf{P}(\mathbf{P h})_{3} \mathbf{C}[4] \mathbf{B u}^{t}-\mathbf{M N P}$ were evaluated for the first time using the three component Mannich reaction of benzaldehyde with aniline and acetophenone in an aqueous media at room temperature. The corresponding Mannich product 4 was isolated in an excellent yield ( $100 \%)$. Optimization experiments, such as changing the amounts of catalyst and water, as well as altering the reaction time, revealed that the yield of Mannich product $\mathbf{4}$ increased as the amount of TMAC[4] Bu${ }^{t}-\mathbf{M N P}$ or $\mathbf{P}(\mathbf{P h})_{3} \mathbf{C}[4] \mathbf{B u}^{t}$ MNP increased (Table 2, entries 16, 17, 22 and 23). Furthermore, the influence of the amount of water on yields was investigated. We found that using $1 \mathrm{~mL}$ of $\mathrm{H}_{2} \mathrm{O}$ in the presence of $\mathbf{P}(\mathbf{P h})_{3} \mathbf{C}[4]$ $\mathbf{B u}^{t}$-MNP or TMAC[4] $\mathbf{B u}^{t}$-MNP gave the highest yields as 62 and 68\% (Table 2, entries 19 and 25), respectively, whereas the lowest yields of Mannich product 4 were afforded when $4 \mathrm{~mL}$ of $\mathrm{H}_{2} \mathrm{O}$ was used in the presence of $\mathbf{P}(\mathbf{P h})_{3} \mathbf{C}[\mathbf{4}] \mathbf{B u}^{t}-\mathbf{M N P}$ or TMAC[4] $\mathbf{B u}^{t}-\mathbf{M N P}$ (Table 2, entries 17 and 23). Although EPPTMS-MN catalyzed this
Mannich reaction in $1 \mathrm{~mL}$ of water to produce product 4 with a yield of $12 \%$ after $72 \mathrm{~h}$ (Table 2, entry 28 ), this percentage is the lowest percentage yield considering the long reaction time. When $\mathbf{P}(\mathbf{P h})_{3} \mathbf{C}[\mathbf{4}] \mathbf{B u}^{t}-\mathbf{M N P}$ and $\mathbf{T M A C}[4] \mathbf{B u}^{t}-\mathbf{M N P}$ were employed as catalysts in $1 \mathrm{~mL}$ of water, the highest yields for Mannich product 4 were obtained as 99.9 and $99.9 \%$, respectively after $72 \mathrm{~h}$ (Table 2, entries 21 and 27). It can be concluded that $\mathbf{P}(\mathbf{P h})_{3} \mathbf{C}[\mathbf{4}] \mathbf{B u}^{t}-\mathbf{M N P}$ and TMAC[4] $\mathbf{B u}^{t}$-MNP exhibited excellent catalytic efficacy with yields $\sim 100 \%$ for Mannich product in an aqueous media.

It is noteworthy that $\mathbf{P}(\mathbf{P h})_{3} \mathbf{C}[4] \mathbf{B u}^{t}-\mathbf{M N P}$ and TMAC[4] $\mathbf{B u}^{t}$ MNP are readily recycled and easily recovered from the reaction mixture due to their magnetic properties. As shown in Table 2 (entries 19 and 25), the reusability results reflected that $\mathbf{P}(\mathbf{P h})_{3} \mathbf{C}$ [4] $\mathbf{B u}^{t}-\mathbf{M N P}$ and TMAC[4] $\mathbf{B u}^{t}$-MNP continued to produce high yields of 62 and $68 \%$, respectively after third runs, which represents efficient sustainable catalytic activity.

\section{Conclusion}

In summary, two novel Lewis acid-type calix[4]arene derivatives ( 2 and 3) containing flexible or bulky groups as well as their corresponding magnetic nanoparticles $\left(\mathbf{P}(\mathbf{P h})_{3} \mathbf{C}[4] \mathbf{B u}^{t}-\mathbf{M N P}\right.$ and TMAC[4] $\left.\mathbf{B u}^{t}-\mathbf{M N P}\right)$ were synthesized and characterized. Moreover, these four Lewis acid-type calix[4]arene derivatives were applied as catalysts in the three component Mannich reaction of benzaldehyde with aniline and acetophenone in an aqueous media. It was found that these calix[4]arene-catalysts were quite capable to catalyze Mannich reaction to form corresponding Mannich product 4 in high yields over a short time. Moreover, catalytic efficacy of bulky groups-substituted calix[4]arene catalyst (Calix-3) was found higher than flexible groupssubstituted calix[4]arene catalyst (Calix-2) under same reaction conditions. In addition, worthy of note is the fact that this effective catalysis system using a catalyst with magnetic property may open potential prospects in 'green' synthesis.

\section{Experimental section}

\section{General}

A TLC plate DC Alufolien Kieselgel 60 F254 (Merck) was used for TLC analyses. An Ez-Melt apparatus in a sealed capillary was employed to determine melting points of the synthesized compounds. ${ }^{1} \mathrm{H}-\mathrm{NMR},{ }^{13} \mathrm{C}-\mathrm{NMR},{ }^{13} \mathrm{C}$-APT, and ${ }^{31} \mathrm{P}-\mathrm{NMR}$ spectra were recorded on a Varian $400 \mathrm{MHz}$ spectrometer. FTIR spectra, and elemental analyses were performed using a Perkin-Elmer 100 spectrometer, and a Leco CHNS-932 analyzer, respectively.

\section{Synthesis of Lewis acid-type calix[4]arene derivatives}

A literature procedure ${ }^{24}$ for the synthesis of $p$-tert-butylcalix[4] arene (1) was applied. Syntheses of 25,27-bis[5-(trimethylammonium bromide)pentyloxyl]-26,28-dihydroxyl-5,11,17,23tetra-tert-butylcalix[4]arene (2 or Calix-2), 25,27-bis[3-(triphenylphosphonium bromide)propyloxyl]-26,28-dihydroxyl-5,11,17,23tetra-tert-butylcalix[4]arene (3 or Calix-3), 25,27-bis[5-(trimethylammonium bromide)pentyloxyl]-26,28-dihydroxyl-5,11,17,23tetra-tert-butylcalix[4]arene-grafted $\mathrm{Fe}_{3} \mathrm{O}_{4}$ nanoparticles (TMAC 
Table 2 Three component Mannich type reaction in the presence of Lewis acid-type calix[4]arene derivatives<smiles>CC(=O)c1ccccc1</smiles>

(4)

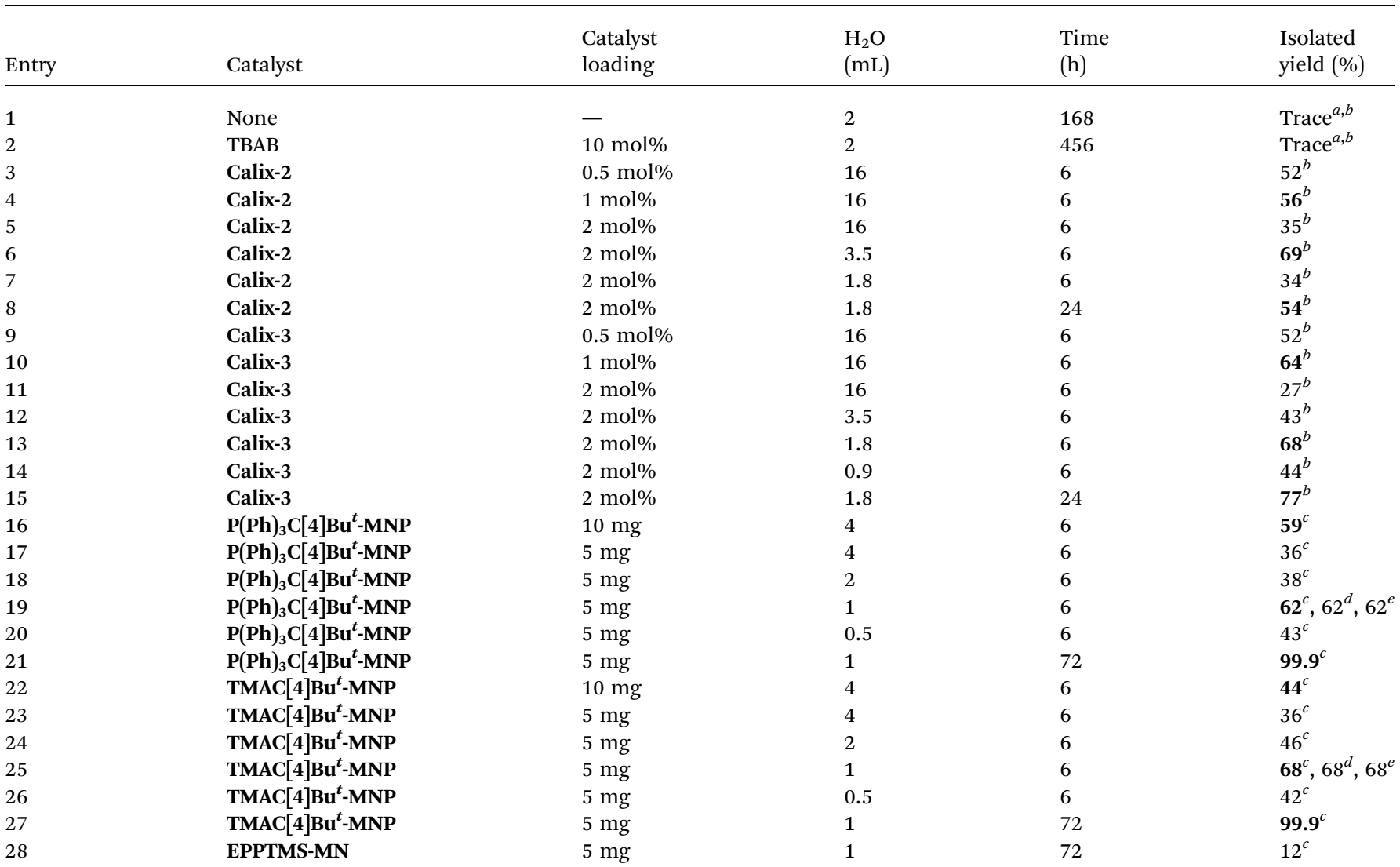

${ }^{a}$ Ref. $4 .{ }^{b}$ Benzaldehyde $(0.23 \mathrm{~g}, 2.19 \mathrm{mmol})$, aniline $(2.19 \mathrm{mmol})$, acetophenone $(2.19 \mathrm{mmol}), \mathrm{NaOH}(11 \mathrm{mmol}), 170 \mathrm{rpm} .{ }^{c}$ Benzaldehyde $(51 \mu \mathrm{L}, 0.5$ $\mathrm{mmol})$, aniline $(0.5 \mathrm{mmol})$, acetophenone $(1.0 \mathrm{mmol}), 170 \mathrm{rpm} .{ }^{d}$ Second reuse of calixarene-based catalysts. ${ }^{e}$ Third reuse of calixarene-based catalysts.

[4] $\mathrm{Bu}^{t}$-MNP) and 25,27-bis[3-(triphenylphosphonium bromide) propyloxyl]-26,28-dihydroxyl-5,11,17,23-tetra-tert-butylcalix[4]arene-grafted $\mathrm{Fe}_{3} \mathrm{O}_{4}$ nanoparticles $\left(\mathbf{P}(\mathbf{P h})_{3} \mathbf{C}[4] \mathbf{B u}^{t}\right.$-MNP) were reported here for the first time.

Synthesis of 25,27-bis[5-(trimethylammonium bromide) pentyloxyl]-26,28-dihydroxyl-5,11,17,23-tetra-tert-butylcalix[4]arene (2 or Calix-2). A mixture of $p$-tert-butylcalix[4]arene 1 (1.0 g, $1.541 \mathrm{mmol})$ and $\mathrm{K}_{2} \mathrm{CO}_{3}(0.53 \mathrm{~g}, 3.853 \mathrm{mmol})$ in anhydrous acetonitrile $(25 \mathrm{~mL})$ was degassed with $\mathrm{N}_{2}$ at $60{ }^{\circ} \mathrm{C}$ for $10 \mathrm{~min}$. To this mixture, (5-bromopentyl)trimethylammonium bromide $(0.94 \mathrm{~g}, 3.267 \mathrm{mmol})$ was added. The reaction mixture was stirred under reflux for $19 \mathrm{~h}$. Then, the solvent was evaporated to dryness, and the residue was dissolved in $\mathrm{CHCl}_{3}(100 \mathrm{~mL})$. This solution was washed with water to adjust $\mathrm{pH}$ 7.0. By evaporation of the solvent, obtained crude product was recrystallized from $\mathrm{MeOH}$, and dried. Yield: $85 \%$, melting point: $241-242{ }^{\circ} \mathrm{C} .{ }^{1} \mathrm{H}-\mathrm{NMR}(400$ $\left.\mathrm{MHz}, \mathrm{CHCl}_{3}\right): \delta 0.91\left(\mathrm{~s}, 18 \mathrm{H}, \mathrm{Bu}^{\dagger}\right), 1.26\left(\mathrm{~s}, 18 \mathrm{H}, \mathrm{Bu}^{\dagger}\right), 1.75-1.79(\mathrm{~m}$, $\left.4 \mathrm{H},-\mathrm{CH}_{2}-\right), 2.04-2.07\left(\mathrm{~m}, 8 \mathrm{H},-\mathrm{CH}_{2}{ }^{-}\right), 3.30(\mathrm{~d}, 4 \mathrm{H}, J=13.2 \mathrm{~Hz}, \mathrm{Ar}-$ $\left.\mathrm{CH}_{2}-\mathrm{Ar}\right), 3.45\left(\mathrm{~s}, 18 \mathrm{H},-\mathrm{CH}_{3}\right), 3.76\left(\mathrm{t}, 4 \mathrm{H}, J=8.0 \mathrm{~Hz}, \mathrm{O}-\mathrm{CH}_{2}-\right), 3.96$ (t, $\left.4 \mathrm{H}, J=5.6 \mathrm{~Hz}, \mathrm{~N}_{-} \mathrm{CH}_{2}-\right), 4.17$ (d, $\left.4 \mathrm{H}, J=13.2 \mathrm{~Hz}, \mathrm{Ar}-\mathrm{CH}_{2}-\mathrm{Ar}\right)$, $6.73(\mathrm{~s}, 4 \mathrm{H}, \mathrm{ArH}), 7.03(\mathrm{~s}, 4 \mathrm{H}, \mathrm{ArH}), 7.11(\mathrm{~s}, 2 \mathrm{H},-\mathrm{OH}) .{ }^{13} \mathrm{C}-\mathrm{NMR}(100$ $\left.\mathrm{MHz}, \mathrm{CDCl}_{3}\right): \delta 22.8\left(-\mathrm{CH}_{2}-\right), 23.0\left(-\mathrm{CH}_{2}-\right), 29.2\left(-\mathrm{CH}_{2}-\right), 31.0$ $\left(\mathrm{Bu}^{t} \mathrm{CH}_{3}\right), 31.7\left(\mathrm{Ar}-\mathrm{CH}_{2}-\mathrm{Ar}\right), 33.8\left(\mathrm{Bu}^{t} \mathrm{C}\right), 33.9\left(\mathrm{~N}^{+}-\mathrm{CH}_{3}\right), 53.5\left(\mathrm{~N}^{+}-\right.$ $\left.\mathrm{CH}_{2}{ }^{-}\right), 66.6\left(\mathrm{O}^{-} \mathrm{CH}_{2}{ }^{-}\right), 125.3,125.5,127.8,132.1,142.0,147.0$, 149.7, 150.1. Anal. calcd for $\mathrm{C}_{60} \mathrm{H}_{92} \mathrm{Br}_{2} \mathrm{~N}_{2} \mathrm{O}_{4}$ (\%): C, 67.65; H, 8.71; N, 2.63. Found (\%); C, 67.59; H, 8.76; N, 2.49.

Synthesis of 25,27-bis[3-(triphenylphosphonium bromide) propyloxyl]-26,28-dihydroxyl-5,11,17,23-tetra-tert-butylcalix[4]arene (3 or Calix-3). To a mixture of $p$-tert-butylcalix[4]arene ( $1 \mathrm{~g}$, $1.541 \mathrm{mmol})$ and potassium carbonate $(0.53 \mathrm{~g}, 3.853 \mathrm{mmol})$ in 
dry acetonitrile $(25 \mathrm{~mL})$ was added (3-bromopropyl)triphenylphosphonium bromide $(1.52 \mathrm{~g}, 3.267 \mathrm{mmol})$. The mixture was stirred under reflux for $38 \mathrm{~h}$. The reaction process was monitored by TLC $\left(\mathrm{CH}_{2} \mathrm{Cl}_{2} /\right.$ hexane, $1 / 1$, (v/v)). After completion of the reaction, the solvent of the mixture was removed under reduced pressure. Remaining product was dissolved in chloroform, and washed with water to adjust pH 7.0. Organic phase was dried over $\mathrm{MgSO}_{4}$, filtered and evaporated to dryness. The crude was recrystallized from $\mathrm{MeOH}$, and dried. Yield: 91\%, melting points: $191-193{ }^{\circ} \mathrm{C}$. FTIR (ATR): $1481 \mathrm{~cm}^{-1}$ (V $\mathrm{V}_{\text {P-Ar }}$, sharp peak). ${ }^{1} \mathrm{H}-\mathrm{NMR}\left(400 \mathrm{MHz}, \mathrm{CHCl}_{3}\right): \delta 0.76\left(\mathrm{~s}, 18 \mathrm{H}, \mathrm{Bu}^{t}\right), 1.23(\mathrm{~s}, 18 \mathrm{H}$, $\mathrm{Bu}^{t}$ ), 2.03 (brs, $4 \mathrm{H},-\mathrm{CH}_{2}-$ ), 3.07 (d, $4 \mathrm{H}, J=13.2 \mathrm{~Hz}, \mathrm{Ar}-\mathrm{CH}_{2}-\mathrm{Ar}$ ), 3.93 (d, 8H, $J=13.2 \mathrm{~Hz}, \mathrm{Ar}_{-} \mathrm{CH}_{2}-\mathrm{Ar}$ and $\mathrm{O}-\mathrm{CH}_{2}-$ ), 4.07 (brs, $4 \mathrm{H}$, P- $\left.\mathrm{CH}_{2}-\right), 6.31$ (s, 2H, $\left.-\mathrm{OH}\right), 6.54$ (s, 4H, ArH), 6.94 (s, 4H, ArH), 7.60-7.77 (m, 30H, ArH). ${ }^{13} \mathrm{C}-\mathrm{NMR}\left(100 \mathrm{MHz}, \mathrm{CDCl}_{3}\right): \delta 19.6\left(\mathrm{P}^{+}-\right.$ $\left.\mathrm{CH}_{2}{ }^{-}\right), 22.7\left(-\mathrm{CH}_{2}{ }^{-}\right), 30.8\left(-\mathrm{CH}_{3}, \mathrm{Bu}^{t}\right), 31.1\left(-\mathrm{CH}_{3}, \mathrm{Bu}^{t}\right), 31.6(\mathrm{Ar}-$ $\left.\mathrm{CH}_{2}-\mathrm{Ar}\right), 33.7\left(-C, \mathrm{Bu}^{t}\right), 33.8\left(-C, \mathrm{Bu}^{t}\right), 74.5\left(\mathrm{O}-\mathrm{CH}_{2}\right), 117.3(-C$, $\mathrm{ArC}), 118.1$ ( $-C, \mathrm{ArC}), 125.2$ ( $-\mathrm{CH}, \mathrm{ArC}), 125.5$ ( $-\mathrm{CH}, \mathrm{ArC}), 127.8$ $(-C, \mathrm{ArC}), 130.7$ ( $-\mathrm{CH}, \mathrm{ArC}), 131.7$ (-C, $\mathrm{ArC}), 133.6(-\mathrm{CH}, \mathrm{ArC})$, 135.3 ( $-\mathrm{CH}, \mathrm{ArC}), 142.2$ ( $-C, \mathrm{ArC}), 147.1$ (O-CAr), 148.7 (O-CAr). ${ }^{31} \mathrm{P}-\mathrm{NMR}\left(121 \mathrm{MHz}, \mathrm{CHCl}_{3}\right): \delta 24.1,24.3,24.4,25.1,29.0$. Anal. calcd for $\mathrm{C}_{86} \mathrm{H}_{96} \mathrm{Br}_{2} \mathrm{O}_{4} \mathrm{P}_{2}$ (\%): C, 72.98; $\mathrm{H}, 6.84$. Found (\%); C, $72.85 ; \mathrm{H}, 6.89$.

\section{General procedure for the immobilizations of Calix-2 and Calix-3 onto EPPTMS-MN}

$\mathrm{NaH}(0.05 \mathrm{~g})$ and EPPTMS-MN $(0.4 \mathrm{~g})$ were added to a solution of calixarene derivative $(0.4 \mathrm{~g})$ in a mixture of THF/DMF $(3 / 1, \mathrm{v} / \mathrm{v})$, respectively. The mixture was stirred under reflux for $72 \mathrm{~h}$. Then, calixarene-grafted nanoparticles was easily separated from the reaction mixture using a simple external magnet, and washed with chloroform in order to remove excess calixarene derivative from the calixarene-grafted magnetic nanoparticles. Obtained calixarene-grafted magnetic nanoparticles were washed with water until neutral $\mathrm{pH}$ was obtained, and dried in an oven.

25,27-Bis[5-(trimethylammonium bromide)pentyloxyl]-26,28dihydroxyl-5,11,17,23-tetra-tert-butylcalix[4] arene-grafted $\mathrm{Fe}_{3} \mathrm{O}_{4}$ nanoparticles (TMAC[4] $\mathrm{Bu}^{t}$-MNP). FTIR (KBr disk) $\mathrm{cm}^{-1}: 3411$ $\left(\mathrm{V}_{\mathrm{OH}}\right), 1657\left(\mathrm{~V}_{\mathrm{H}_{2} \mathrm{O}}\right), 1479,1414\left(\mathrm{~V}_{\mathrm{C}=\mathrm{C}}\right), 1084\left(\mathrm{~V}_{\mathrm{Si}-\mathrm{O}}\right), 796\left(\mathrm{~V}_{\mathrm{Si}-\mathrm{O}}\right)$ ve $563\left(\mathrm{~V}_{\mathrm{Fe}-\mathrm{O}}\right)$. Anal. Found (\%); C, 16.24; H, 3.51; N, 0.19.

25,27-Bis[3-(triphenylphosphonium bromide)propyloxyl]26,28-dihydroxyl-5,11,17,23-tetra-tert-butylcalix[4] arene-grafted $\mathrm{Fe}_{3} \mathrm{O}_{4}$ nanoparticles $\left(\mathrm{P}(\mathrm{Ph})_{3} \mathrm{C}[\mathbf{4}] \mathrm{Bu}^{t}\right.$-MNP). FTIR ( $\mathrm{KBr}$ disk) $\mathrm{cm}^{-1}$ : $3405\left(\mathrm{~V}_{\mathrm{OH}}\right), 1657\left(\mathrm{~V}_{\mathrm{H}_{2} \mathrm{O}}\right), 1479\left(\mathrm{~V}_{\mathrm{P}-\mathrm{Ar}}\right), 1447,1411\left(\mathrm{~V}_{\mathrm{C}=\mathrm{C}}\right)$, $1207\left(\mathrm{~V}_{\mathrm{C}-\mathrm{O}-\mathrm{C}}\right), 1091\left(\mathrm{~V}_{\mathrm{Si}-\mathrm{O}}\right), 796\left(\mathrm{~V}_{\mathrm{Si}-\mathrm{O}}\right)$ ve $557\left(\mathrm{~V}_{\mathrm{Fe}-\mathrm{O}}\right)$.

\section{Typical procedure for Mannich reaction in the presence of} Lewis acid-type calix[4] arene catalysts

A reported literature procedure was applied.,27,28 Typically, calixarene-based catalysts was treated with $\mathrm{NaOH}$ in water (as listed in the table), and were added aldehyde, anilin and acetophenone, respectively. The reaction mixture was stirred at room temperature for the period of time (as given in the table). The crude was then purified by column chromatography $\left(\mathrm{SiO}_{2}\right.$, ethylacetate/hexane). Melting points: $171-172{ }^{\circ} \mathrm{C} .{ }^{1} \mathrm{H}-\mathrm{NMR}(400$
$\mathrm{MHz} \mathrm{CDCl}_{3}$ ): $\delta 3.27$ (dd, $1 \mathrm{H}, J=4.8,12.4 \mathrm{~Hz},-\mathrm{CH}_{2}-$ ), 3.62 (dd, $\left.1 \mathrm{H}, J=9.2,8.0 \mathrm{~Hz},-\mathrm{CH}_{2}-\right)$, 4.95-5.00 (m, $\left.1 \mathrm{H},-\mathrm{CH}-\right), 6.22$ (d, $1 \mathrm{H}$, $J=7.6 \mathrm{~Hz}$, Ar-NH-) $6.42-6.49(\mathrm{~m}, 3 \mathrm{H}, \mathrm{ArH}), 6.95(\mathrm{t}, 2 \mathrm{H}, J=$ $8.4 \mathrm{~Hz}, \mathrm{ArH}), 7.16(\mathrm{t}, 1 \mathrm{H}, J=7.6 \mathrm{~Hz}, \mathrm{ArH}), 7.27(\mathrm{t}, 2 \mathrm{H}, J=7.6 \mathrm{~Hz}$, ArH), 7.44 (d, 2H, $J=7.2 \mathrm{~Hz}, \operatorname{ArH}), 7.50$ (t, 2H, $J=8.0 \mathrm{~Hz}, \operatorname{ArH})$, $7.62(\mathrm{t}, 1 \mathrm{H}, J=7.6 \mathrm{~Hz}, \operatorname{ArH}), 7.95(\mathrm{~d}, 2 \mathrm{H}, J=6.8 \mathrm{~Hz}, \operatorname{ArH})$ (Fig. S10; see ESI $\dagger$ ). ${ }^{13} \mathrm{C}-\mathrm{NMR}\left(100 \mathrm{MHz}, \mathrm{CDCl}_{3}\right): \delta 46.2(-\mathrm{CH})$, $54.9\left(-\mathrm{CH}_{2}\right), 114.0(\mathrm{ArC}), 118.0(\mathrm{ArC}), 126.4(\mathrm{ArC}), 127.4(\operatorname{ArC})$, 128.2 (ArC), $128.7(\operatorname{ArC}), 128.8(\operatorname{ArC}), 129.1(\operatorname{ArC}), 133.5(\operatorname{ArC})$, 136.6 $(\mathrm{ArC}), 142.8(\mathrm{ArC}), 146.7(\mathrm{~N}-C \mathrm{Ar}), 198.2(C=\mathrm{O})$ (Fig. S11; see ESI $\dagger$ ). Anal. calcd for $\mathrm{C}_{21} \mathrm{H}_{19} \mathrm{NO}(\%)$ : C, 83.69; H, 6.35; N, 4.65. Found (\%): C, 83.59; H, 6.48; N, 4.51.

\section{References}

1 M. Arend, B. Westermann and N. Risch, Angew. Chem., Int. Ed., 1998, 37, 1044-1070.

2 W.-B. Yi and C. Cai, J. Fluorine Chem., 2006, 127, 1515-1521.

3 Q. Tang, H.-J. Quan, S. Liu, L.-T. Liu, C.-F. Chow and C.-B. Gonga, J. Mol. Catal. A: Chem., 2016, 421, 37-44.

4 S. Sayin and M. Yilmaz, RSC Adv., 2014, 4, 2219-2225.

5 (a) B. List, P. Pojarliev, W. T. Biller and H. J. Martin, J. Am. Chem. Soc., 2002, 124, 827-833; (b) P. Hermange, M. E. T. H. Dau, P. Retailleau and R. H. Dodd, Org. Lett., 2009, 11, 4044-4047.

6 H. Ishitani, M. Ueno and S. Kobayashi, J. Am. Chem. Soc., 2000, 122, 8180-8186.

7 R. Müller, H. Goesmann and H. Waldmann, Angew. Chem., Int. Ed., 1999, 38, 184-187.

8 H. Wu, Y. Shen, L. Y. Fan, Y. Wan, P. Zhang, C. F. Chen and W. X. Wang, Tetrahedron, 2007, 63, 2404-2408.

9 Y. Wu, C. Chen, G. Jia, X. Y. Zhu, H. M. Sun, G. F. Zhang, W. Q. Zhang and Z. W. Gao, Chem.-Eur. J., 2014, 20, 85308535 .

10 K. Nagata, Y. Kuga, A. Higashi, A. Kinoshita, T. Kanemitsu, M. Miyazaki and T. Itoh, J. Org. Chem., 2013, 78, 7131-7136.

11 H. G. O. Alvim, G. A. Bataglion, L. M. Ramos, A. L. de Oliveira, H. C. B. de Oliveira, M. N. Eberlin, J. L. de Macedo, W. A. da Silva and B. A. D. Neto, Tetrahedron, 2014, 70, 3306-3313.

12 L. Mengozzi, A. Gualandi and P. G. Cozzi, Chem. Sci., 2014, 5, 3915-3921.

13 S. Kobayashi, T. Hamada and K. Manabe, J. Am. Chem. Soc., 2002, 124, 5640-5641.

14 T. Akiyama, J. Takaya and H. Kagoshima, Adv. Synth. Catal., 2002, 344, 338-347.

15 S. Sayin, E. Akoz and M. Yilmaz, Org. Biomol. Chem., 2014, 12, 6634-6642.

16 (a) T. Klejch, J. Slavíček, O. Hudeček, V. Eigner, N. A. Gutierrez, P. Cuřínová and P. Lhoták, New J. Chem., 2016, 40, 7935-7942; (b) Y. Yeon, S. Leem, C. Wagen, V. M. Lynch, S. K. Kim and J. L. Sessler, Org. Lett., 2016, 18, 4396-4399.

17 (a) S. Memon, A. A. Bhatti, A. A. Bhatti and I. B. Solangi, Desalin. Water Treat., 2016, 57, 1844-1856; (b) S. Akın, M. Gülen, S. Sayin, H. Azak, H. B. Yıldız and S. Sönmezoğlu, J. Power Sources, 2016, 307, 796-805. 
18 P. Sarkar and C. Mukhopadhyay, Green Chem., 2016, 18, 6556-6563.

19 A. Casnati, Chem. Commun., 2013, 49, 6827-6830.

20 S. Sayin, H. Azak, H. B. Yildiz, P. Camurlu, G. U. Akkus, L. Toppare and M. Ersoz, Phys. Chem. Chem. Phys., 2015, 17, 19911-19918.

21 (a) V. Bagnacani, V. Franceschi, L. Fantuzzi, A. Casnati, G. Donofrio, F. Sansone and R. Ungaro, Bioconjugate Chem., 2012, 23, 993-1002; (b) F. Özcan, M. Bayrakcı and Ş. Ertul, J. Inclusion Phenom. Macrocyclic Chem., 2016, 85, 49-58; (c) R. Salvio, S. Volpi, R. Cacciapaglia, F. Sansone, L. Mandolini and A. Casnati, J. Org. Chem., 2016, 81, 9012-9019; (d) E. Ozyilmaz, M. Bayrakci and M. Yilmaz, Bioorg. Chem., 2016, 65, 1-8; (e) S. Memon, A. A. Bhatti, A. A. Bhatti, Ü. Ocak and M. Ocak, J. Fluoresc., 2016, 26, 1591-1599.

22 (a) S. Sayin and M. Yilmaz, Tetrahedron, 2016, 72, 6528-6535; (b) M. De Rosa, P. La Manna, A. Soriente, C. Gaeta, C. Talotta and P. Neri, RSC Adv., 2016, 6, 91846-91851; (c) S. Sayin and M. Yilmaz, Tetrahedron, 2014, 70, 6669-6676.
23 M. Rahman, I. Ling, N. Abdullah, R. Hashim and A. Hajra, RSC Adv., 2015, 5, 7755-7760.

24 C. D. Gutsche, Single step synthesis and properties of calixarenes In Calixarenes: A Versatile Class of Macrocyclic Compounds, ed. Vicens, Topics in Inclusion Science, 1990, vol. 3, pp. 3-37.

25 (a) L. Zeng, K. Luo and Y. Gong, J. Mol. Catal. B: Enzym., 2005, 38, 24-30; (b) Y. Yong, Y. Bai, Y. Li, L. Lin, Y. Cui and C. Xia, J. Magn. Magn. Mater., 2008, 320, 2350-2355.

26 S. Sayin and M. Yilmaz, J. Chem. Eng. Data, 2011, 56, 20202029.

27 W. Shen, L.-M. Wang and H. Tian, J. Fluorine Chem., 2008, 129, 267-273.

28 (a) K. Manabe and S. Kobayashi, Org. Lett., 1999, 1, 19651967; (b) T. Ollevier and E. Nadeau, J. Org. Chem., 2004, 69, 9292-9295; (c) T. Akiyama, K. Matsuda and K. Fuchibe, Synlett, 2005, 322-324; (d) N. Azizi, L. Torkiyan and M. R. Saidi, Org. Lett., 2006, 8, 2079-2082. 